\title{
O trabalho dos Agentes Comunitários de Saúde (ACS) na política de HIV/AIDS
}

\section{El trabajo de los Agentes Comunitarios en Salud en las políticas de HIV/sida}

\section{Community health agent practice at HIV/sida politics}

\author{
Kátia Bones Rocha \\ ORCID ID: 0000-0001-7603-1709
}

Pontifícia Universidade Católica do Rio Grande do Sul (PUCRS), Brasil

Ana Carolina Tittoni da Silveira ORCID ID: 0000-0001-8495-0473

Pontifícia Universidade Católica do Rio Grande do Sul (PUCRS), Brasil

Aline Fernanda Giacomelli Gazzola ORCID ID: 0000-0001-7320-917X Pontifícia Universidade Católica do Rio Grande do Sul (PUCRS), Brasil

Dandara Varela da Silva ORCID ID: 0000-0003-4665-4950 Pontifícia Universidade Católica do Rio Grande do Sul (PUCRS), Brasil

Raphaela Popoviche Eifler ORCID ID: 0000-0003-0628-2689 Pontifícia Universidade Católica do Rio Grande do Sul (PUCRS), Brasil

Autor referente: katiabonesrocha@gmail.com

Historia editorial Recibido: 14/02/2020 Aceptado: 06/08/2020

\section{RESUMO}

O trabalho dos Agentes Comunitários de Saúde (ACS) na política de HIV/Aids está em construção nas equipes de atenção básica $(A B)$. $O$ presente estudo teve como objetivo analisar os atravessamentos relacionados a temática de HIV/Aids na atuação dos ACS a partir da interlocução dos atores envolvidos, tendo em vista que se trata de uma política em disputa. Utilizou-se 
- método qualitativo exploratório. A coleta de dados foi realizada em 15 unidades de saúde de Porto Alegre. Utilizou-se um recorte de 14 entrevistas com profissionais da atenção básica e da gestão em HIV/Aids compreendidas e analisadas através da análise temática. Os resultados agrupam-se em: a) Potência e Função dos ACS; b) Inserção dos ACS na equipe; c) HIV e Território. O trabalho dos ACS mostrase uma potente via de promoção e prevenção relacionada a política de HIV/Aids nos cotidianos de prática, tendo em vista que trazem a cultura e demandas locais à equipe, funcionando como um elo entre o território e a unidade. No entanto, nem sempre esses são reconhecidos enquanto parte das equipes. Tratando-se do estigma relacionado ao HIV/Aids, percebeu-se que os ACS ocupam uma posição paradoxal, já que, por vezes, residem na mesma comunidade dos usuários, o que pode complexizar as relações de trabalho e sigilo. Assim, há lacunas na consolidação do ofício dos ACS como a falta de investimentos na formação específica e no desenvolvimento de seu fazer, que se desdobram no relacionamento com a equipe e os usuários do serviço, podendo obstaculizar os processos de trabalho previstos.

Palavras-chave: Sistema único de saúde; atenção básica; agentes comunitários de saúde; hiv/aids.

\section{RESUMEN}

El trabajo de los Agentes Comunitarios de Salud (ACS) en la política de $\mathrm{VIH} / \mathrm{SIDA}$ en la comunidad está en construcción en los equipos de Atención Primaria (AP). El estudio tuvo como objetivo analizar las cuestiones relacionadas con $\mathrm{VIH} / \mathrm{SIDA}$ en la actuación del ACS a partir del análisis del diálogo de los actores involucrados. Es un estudio de método cualitativo exploratorio. La recogida de datos se realizó en 2015 en 15 unidades de salud de AP en Porto Alegre (Brasil). Se ha utilizado un recorte de 14 entrevistas con profesionales de la $A B$ y gestión del $\mathrm{VIH} / \mathrm{SIDA}$. Los resultados se agruparon en categorías: a) Potencia y función de los ACS; b) Inserción del ACS en el equipo; c) VIH y Territorio Comunidad. El trabajo del ACS es una forma de promoción y prevención relacionada con la política del $\mathrm{VIH} / \mathrm{SIDA}$ en la práctica cotidiana, porque aportan la cultura y demandas locales al equipo, funcionando como un enlace entre la comunidad y la unidad de salud. Sin embargo, ni siempre los ACS son reconocidos como parte del equipo. Además, el estigma relacionado con el $\mathrm{VIH} / \mathrm{SIDA}$, pone a los ACS en una posición paradójica, ya que por veces residen en la misma comunidad de los pacientes, lo que puede hacer más complejas las relaciones de trabajo y anonimato. Concluyendo, faltan inversiones en la formación y en el desarrollo del trabajo de los ACS. Estas deficiencias se ponen en la relación con el equipo y usuarios del servicio, lo que puede dificultar el trabajo planeado.

Palabras-clave: Sistema unico de salud; atención primaria; agentes comunitarios de salud; vih/sida. 


\section{ABSTRACT}

The Community health agent practice at $\mathrm{HIV} /$ sida is still an emerging thematic at Primary Care and its team. This study aims to analyse the crossings between Community health agent practice dealing with HIV/sida from the social actors interlocution. It needs to be considered as a political dispute. The study used an exploratory qualitative method. The data collection was made in 2015, covering 15 Basic Health Units in Porto Alegre, Brazil. A cut-off of 14 healthcare professionals and $\mathrm{HIV} /$ sida management of different qualifications was used. The Thematic content analysis was used and the results were grouped into: a) Community health agent practice and power; b) Community health agent entry on the team; c) HIV and territory. The Community health agent practice is shown as a powerful key to provide promotion and prevention in healthcare daily routine: the professionals are engaged with the community culture and responsible to bring its demands to the healthcare team, being a connecting element between the community and the team. However, they are not usual recognised as a part of the the practice and healthcare teams. Besides, as regards $\mathrm{HIV} /$ sida stigma, it was perceived that the agents occupy a paradoxal position by living on the same community as the users. It can complexifies the teamwork relations and informations secrecy. Thus, there are gaps and lack of investments in qualification of their work. These failures reflects in the relationship with the teamwork and the users - it can hinder expected work processes.

Keywords: Unified health system; primary care; community health workers; hiv/sida.

$\mathrm{O}$ Sistema Único de Saúde (SUS) brasileiro trabalha a partir de uma lógica de universalidade, integralidade e equidade do acesso. Assim, foca em ações de prevenção, promoção e recuperação em saúde, sendo a Atenção Básica (AB) - ou atenção primária à saúde- o principal mecanismo de ação. A Política Nacional de Atenção Básica (PNAB) foi criada em 2011 e propõe diretrizes para a AB e para a operacionalização da Estratégia Saúde da Família (ESF) e do Programa de Agentes Comunitários de Saúde (Pacs). A ESF tem como equipe mínima: médicos, enfermeiros, técnicos de enfermagem e Agentes Comunitários em Saúde (ACS) (Brasil, 2012). 
Gomes, Gutiérres e Soranz (2020), apresentam em seu estudo o aumento na cobertura da ESF em território nacional, porém tais números ainda estão consideravelmente abaixo dos valores estimados para a realidade atual. Quando analisados os dados referentes ao Rio Grande do Sul, podemos ver um aumento em comparação com o resto do país. De acordo com dados obtidos no website da Atenção Básica no Estado do Rio Grande do Sul (https://atencaobasica.saude.rs.gov.br, recuperado em 21, julho, 2020) a cobertura das ESF consegue ultrapassar a marca de $60 \%$, enquanto no Brasil apresenta-se abaixo de $50 \%$.

Em 2017 a PNAB sofreu reformulações em sua estrutura, principalmente no tangente à função dos ACS, que deixam de compor a equipe mínima da ESF, sendo facultativa a sua participação. Desde então, a PNAB segue sendo modificada, tendo sua última versão em 2019 (Gomes, Gutiérres \& Soranz, 2020).

A PNAB orienta a atuação do ACS com as famílias em base geográfica definida (territorialidade), cadastramento de usuários da comunidade, orientação quanto à utilização dos serviços disponíveis, visitas domiciliares e acompanhamento, busca por ações que integrem a equipe e a população cadastrada, desenvolvimento de atividades de promoção, prevenção e vigilância à saúde e contato permanente com as famílias em ações multidisciplinares de atenção (Brasil, 2012). Idealiza-se que o trabalho do ACS seja ancorado em processos de educação permanente em saúde produzindo reflexões e ferramentas técnicas que possibilitem seu ofício (Marzari, Junges \& Selli, 2011).

Quando avaliado em outros países como Chile (Santander, 2017), Paraguai (Dullak et al., 2011), Perú (Christensen, 1990) e Angola (Macaia, 2014) o agente de saúde é associado a uma maior busca e utilização dos serviços de saúde e maior atenção às especificidades culturais locais. Em diferentes contextos, o ACS é visto como potencial para melhorar o acesso dos usuários aos serviços e facilitar a circulação de 
informações de prevenção e promoção de saúde no território em que atua (Dullak et al., 2011; Christensen, 1990; Santander, 2017).

No Brasil, em função da alta incidência de HIV/Aids, o MS implementou em 2012 o teste rápido em toda a rede básica de saúde (Rocha, Ew, Moro, Zanardo \& Pizzinato, 2018). Nesse sentido, o mesmo mostra-se uma estratégia eficaz e confiável, com curto tempo de espera do resultado, disponível no SUS (Pizzinato, Rocha, OliveiraMachado, Carvalho \& Nogueira-Freire, 2018).

A construção sócio-histórica do sujeito com HIV/Aids está associada aos grupos de risco (pessoas com comportamentos sexuais fora da norma e/ou que fazem uso de drogas), característicos da disseminação e da falta de estudos acerca da epidemia em 1980 (Seffner \& Parker, 2016). É necessária a revisão de práticas e crenças com relação ao tratamento atualmente. Neste sentido, estudos discutem como as crenças associadas à ideia de grupos de risco e o estigma em relação ao HIV/Aids ainda estão presentes na narrativa de usuários e profissionais, tanto no contexto da $A B$ (Ew, Ferreira, Moro \& Rocha, 2018), como na atenção especializada (Hamann, Pizzinato, Weber \& Rocha, 2017).

As capacitações existentes no campo não dão conta das produções discursivas acerca do estigma do cuidado em HIV/Aids, conforme literatura. A partir da construção deste cuidado, práticas assistencialistas e individualizadas - no sentido de culpabilização do sujeito - reforçam tabus ancorados em concepções biomédicas, além de reproduzir crenças estigmatizantes que se tornam impeditivas ao acesso dos usuários nos serviços de saúde. Fatores como ao sigilo da equipe, a discriminação e à identificação do usuário repercutem negativamente na adesão ao tratamento e ao acompanhamento em saúde (Silva \& Cardoso, 2008; Seoane \& Fortes, 2009; Ew, Ferreira, Moro \& Rocha, 2018).

Neste sentido, o terreno no qual o ACS se inscreve é estruturado a partir de aspectos multifatoriais relacionados aos determinantes sociais da saúde. Tendo isso em vista, 
esse profissional assume um papel paradoxal dentro da equipe, principalmente por ser morador da área adscrita e por ser o dispositivo social de ações voltadas à prevenção e promoção (Zambenedetti \& Both, 2013).

Os ACS identificam o HIV/Aids como um assunto de difícil abordagem na comunidade, considerando que falar sobre o portador de HIV/Aids e sobre o diagnóstico em si atravessa os aspectos de territorialidade e da privacidade (Zambenedetti \& Both, 2013). Falar sobre HIV/Aids pode carregar o sentido de invasão da privacidade e ofensa, propiciando o distanciamento cidadão/profissional e marginalização dessas pessoas nos serviços de saúde. Assim, o status sorológico positivo pode ter influência na efetividade das possíveis estratégias de cuidado (Seoane \& Fortes, 2009).

Estudos nacionais tensionam sua atuação, apontando defasagens na descrição da prática desses profissionais na política de HIV/Aids, o que é de suma importância para que sejam construídas políticas públicas e intervenções efetivas no campo (Seoane \& Fortes, 2009; Pedraza \& Santos, 2017). Sendo assim, o presente estudo objetiva analisar os atravessamentos relacionados à temática de HIV/Aids na atuação dos ACS a partir da interlocução dos atores envolvidos, tendo em vista que se trata de uma política em disputa.

\section{Método}

Trata-se de um estudo qualitativo de caráter exploratório e descritivo (Flick, 2009). A coleta de dados foi realizada no ano de 2015 em 15 unidades de saúde da $A B$ de Porto Alegre, sendo oito Unidades Básicas de Saúde (UBS) tradicionais e sete unidades com Equipes de Saúde da Família (ESF). A escolha das unidades foi realizada mediante sorteio, elegendo-se duas unidades de cada gerência distrital de saúde, sendo que uma delas não aceitou participar da pesquisa. O sorteio foi realizado entre os oito serviços que mais realizavam o teste rápido para HIV/Aids e outras Infecções Sexualmente Transmissíveis (ISTs) e os oito serviços que menos 
realizavam, contando com a unidade de saúde que não aceitou participar da pesquisa. Esses dados foram disponibilizados pela Coordenação de HIV/Aids da Secretaria Municipal de Saúde, a partir de um levantamento interno.

Entre os profissionais e gestores da $A B$, foram entrevistados: enfermeiros, técnicos de enfermagem, agentes comunitários de saúde (ACS), médicos ginecologistas e da família, dentistas, nutricionistas e psicólogos. No total, foram realizadas 79 entrevistas por conveniência, porém neste estudo foi utilizado um recorte de 14 participantes que abordaram a temática do ACS.

Foram realizadas entrevistas semidirigidas que abordaram a implantação do teste rápido e do aconselhamento em HIV/Aids e outras ISTs no contexto da $A B$. As entrevistas tiveram duração média de 30 minutos, foram gravadas, transcritas e analisadas a partir da análise temática (AT) de Braun e Clarke (2013). A leitura na íntegra das entrevistas levou à identificação de temáticas frequentes. Integrou-se os temas elencados, criando as categorias: a) Potência e Função dos ACS; b) Inserção dos ACS na equipe; c) HIV/Aids e Território. Os fragmentos citados foram enumerados em "P1", "P2" e assim por diante.

O presente estudo integra a pesquisa intitulada "Avaliação do processo de implantação da política de descentralização do teste rápido de HIV na $A B$, a partir da percepção de matriciadores, profissionais e usuários", que teve apoio financeiro do Projeto Universal (CNPq). Para a realização da coleta de dados foram preservados todos os aspectos éticos, resguardados pela Resolução ํㅡ 466/2012 do Conselho Nacional de Saúde (CNS), sendo a pesquisa submetida e aprovada pelos Comitês de Ética em Pesquisa (CEP) da Pontifícia Universidade Católica do Rio Grande do Sul (Parecer no 922.644) e da Secretaria Municipal de Saúde de Porto Alegre (Parecer ํo 981.527). 


\section{Resultados}

\section{Potência e Função dos ACS}

Inicialmente, aponta-se a potência do lugar de elo de ligação entre equipe e comunidade ocupado pelos ACS. Para o trabalho da equipe, a potência está no fato de que os ACS conhecem o território e trazem a cultura e demandas locais ao serviço de saúde:

Com conhecimento do lugar porque os agentes tão aqui já faz tempo morando e tudo isso. Então como sempre cobrem esses lugares, sabem alguma situação de risco, alguma coisa assim, até eles mesmos falam pra vir no posto e fazer o teste rápido também. Em geral, agente comunitário tem uma função bem importante. $(\mathrm{P} 1)$

Os próprios ACS também remetem e reconhecem os êxitos de seu trabalho enquanto elo. Pode-se observar que para além de conhecimentos culturais, estes identificam demandas estruturais e de serviço, tendo em vista sua circulação pelo território:

A gente faz a identificação na área. Essa identificação trazemos para o enfermeiro ou para o médico e aí assim a gente consegue realizar alguma coisa, uma reunião de equipe ou mesmo na conversa com o profissional da assistência. Idealizando isso, a gente consegue concretizar com a área né, por exemplo assim: eu vou lá, vejo que tem 3, 4 meninas que se interessaram em fazer o teste rápido, de uma orientação mais específica e talvez até de uma coleta de Papanicolau, trago essa demanda para o enfermeiro ou para o médico. (P2)

Também, devido aos vínculos já consolidados no território, o ACS consegue acessar espaços que outros profissionais da equipe não teriam conhecimento ou possibilidade. Relacionado a isto, uma participante traz o exemplo de casas de sexo remunerado:

Como a gente tem agentes de saúde que trabalham, vivem, conhecem a região... no primeiro momento é difícil você conseguir entrar na região. Tem 
que ter muito vínculo com o agente de saúde da área lá, então o agente foi até os cafetões, ver se iam liberar... então assim, primeiro a gente foi contribuindo para que não se propagasse a questão da doença e do vírus, levando camisinha, preservativo, orientando, oferecendo serviço de saúde quando preciso. (P3)

Em relação às especificidades do trabalho dos ACS na política de HIV/Aids na $A B$, foram referidas duas principais frentes de ação. A primeira se refere ao cadastramento de novas famílias e a segunda relacionada à adesão ao tratamento de usuários que tem um resultado positivo no teste rápido para alguma Infecção Sexulamente Transmissível (IST) e/ou seus parceiros. A partir disto, é tensionada na fala dos participantes a linha tênue entre o cuidado e o controle no fazer dos ACS:

A gente teve um caso de uma gestante que deu positivo e ela já disse 'meu marido não vem, ele é ignorante, não vai vir, ele não gosta'. Então o agente de saúde foi na casa, conversou, se ele aceitava ter que fazer o teste. E ele aceitou. (P4)

Nesta linha, outro ponto a destacar quanto ao fazer na política de HIV/Aids diz respeito a ações pontuais ou longitudinais de promoção e educação em saúde. Alguns ACS realizavam grupos vinculados ao Programa Saúde na Escola (PSE) de prevenção à IST, bem como, atividades em espaços comunitários, como boates onde trabalham profissionais do sexo:

Tivemos o momento que decidimos fazer um acompanhamento lá dentro. Nós conseguimos e o resultado foi satisfatório porque muitas delas [profissionais do sexo] não tinham. A gente conseguiu reforçar pra que cada vez mais utilizem e continuem utilizando o preservativo. E aquelas que não utilizavam e não adquiriram [IST], comecem a fazer uso do preservativo, que é a única forma, que vocês podem não pegar se continuarem com a mesma atividade e mesmo risco, se expondo. (P5) 
Também são referidas atividades de promoção de saúde realizadas na própria unidade. A sala de espera mostrou-se eficaz como ferramenta informativa e de busca pelo teste rápido:

A gente tem também as salas de espera, que às vezes em certas datas os agentes vão lá e orientam as pessoas, entregam folders, já faz um aconselhamento ali. Que é a melhor forma de pegar os usuários. Quando estão esperando ali na frente. (P6)

Neste sentido, a partir do panorama apresentado, percebe-se que a inserção dos ACS na equipe é fundamental para a condução das atividades previstas no território. Seu fazer é uma possibilidade de repensar estratégias de cuidado, promovendo a integralidade, manutenção do acesso ao serviço e prevenção em saúde.

\section{Inserção dos ACS na equipe}

Tratando-se de relacionamentos da equipe, médicos, enfermeiros e técnicos de enfermagem trazem falas que indicam uma hierarquia de funções, na qual o ACS é colocado, por vezes, como um profissional à parte da equipe. Em momentos referemse aos agentes como "eles", e a equipe de saúde como "nós", criando uma dicotomia que pode afastar o ACS de seu serviço, assim como da comunidade, e inviabilizar ações de cuidado em saúde:

Eu não vejo nenhum preconceito com relação aos médicos, enfermeiros.... Eu acho que os agentes por estarem aqui na comunidade, conhecerem aquela pessoa de outras maneiras... neles eu visualizo mais o preconceito. Porque eles conhecem a família, sei lá. (P7)

Em se tratando da presença do ACS nas práticas em saúde, os profissionais entrevistados trazem que, em alguns momentos, que estes atuam como um entrave entre o serviço e os usuários. Por vezes, no discurso dos participantes, o ACS é 
responsabilizado por produzir barreiras de acesso tocantes à política de HIV/Aids no território:

A gente faz as orientações. O agente de saúde assim, ele não tem um quesito de uma capacitação técnica, ele não é um profissional de uma formação técnica, entendeu? Então a gente acompanha o processo no nível mais de orientação, não no nível técnico quanto os profissionais da enfermagem, da assistência em geral. (P8)

Em contraponto, percebe-se que alguns profissionais participantes concebem os ACS enquanto parte da equipe. Assim, reconhecem a potência e a importância destes para o cotidiano de trabalho:

E a gente sempre bate na tecla dos agentes, que estão mais próximos, tem mais vínculo, então a gente sempre pergunta se eles estão com alguma dúvida, a agente já passou pra eles como é o teste, como é feito, então eles já são mais orientados para poder orientar as pessoas para vir também. (P6)

Nesta direção, conceber os ACS como parte importante dos processos de trabalho, corrobora com a garantia da integralidade e universalidade do acesso à saúde dos usuários. Sendo ilustrado por meio da fala de uma profissional:

Sempre tem que contar para um agente de saúde, porque ele tem que acompanhar aquele usuário. Eventualmente ele tem que ir na casa, saber se ele foi fazer a coleta, se tá tomando medicamentos, então o agente de saúde sempre tem que saber. Mas nas reuniões a gente sempre fala sobre isso, que não pode comentar no saguão, no corredor, que alguém pode ouvir. (P9)

Considerando que o fazer dos ACS ainda é um território em construção, alguns dispositivos vêm sendo utilizados para possibilitar a maior inserção deles nas equipes. Percebe-se nas entrevistas que as unidades que realizavam reuniões de equipe sistemáticas com a presença dos ACS, bem como incluíam-nos nos processos de capacitação ao teste rápido de HIV/Aids, mostravam maior abertura para repensar 
seus processos de trabalho de forma geral. Além disso, passavam a englobar todos os saberes da equipe nos acompanhamentos:

Acredito que não é só nós... Tem muito preconceito, é bem complicado... A gente tem usuário HIV/Aids... estuda um monte sobre e tu não diz que ela tem. Ela é super saudável e ela diz: Ah eu não venho aqui porque o agente de saúde me conhece... O agente de saúde tem que demonstrar segurança que não vai expor. Então, essa vez deu positivo. Aí ela já fica 'Agora todo mundo vai ficar sabendo'. Então, a equipe tem que demonstrar segurança e a pessoa aceitar que a gente não vai expor. (P10)

\section{HIV/Aids e Território}

Abordar a temática do trabalho dos ACS na política de HIV/Aids na AB remete a olhar também para os efeitos do estigma e preconceitos históricos direcionados aos portadores do vírus do HIV. Uma participante responsável pelo processo de matriciamento em HIV/Aids evidencia as repercussões do estigma na vida dos sujeitos:

Muitos usuários dizem 'não, eu sei que o HIV não é o fim da vida' alguns ainda se assustam muito, não dá pra banalizar a notícia, o diagnóstico como esse não é banal... alguns dizem 'não, eu sei, não é isso que me preocupa, o que me preocupa é o estigma...' então eles morrem de medo de ter e sua sorologia ser revelada no seu território, e que eles tem toda a razão, efetivamente pode ser o fim da vida deles, não concreta mais aquela coisa da morte civil. (P11)

Um dos tópicos abordados nas entrevistas era se os profissionais realizariam o teste rápido de HIV, sífilis e hepatites virais nas unidades básicas de saúde de seus territórios de residência. Uma participante refere: 
Eu faria [teste rápido], mas talvez pudesse ser um fator limitante mesmo, fazer no teu bairro com pessoas conhecidas talvez, vão saber que tu é, mais o medo de que essa pessoa possa contar para um vizinho. (P12)

Neste sentido, percebe-se que os desdobramentos da implementação da política de teste rápido neste contexto vai além da presença e circulação dos ACS nas equipes. $O$ tema do medo e risco de rompimento com o sigilo, atravessam o encontro da unidade com o território, o que fica evidenciado na fala de um ACS:

Aconteceu de eu largar leite na casa de uma usuária e um dia ela não estava. Ela deixou dito para um vizinho que era para ele pegar o leite porque ela não ia estar. Aí o vizinho disse 'Eu to sabendo que tu veio deixar o leite pode deixar comigo'. Aí depois a mulher do vizinho veio me questionar porque que ela ganhava leite... ela não pensou nisso né que ela pedindo para o vizinho pegar o leite dela o outro vizinho ia querer saber 'Porque que ela ganha e eu não ganho?' Aí eu tive que contar história para não falar o real problema! Então, às vezes tem que ter esse cuidado e não esquecer desse detalhe. Porque isso poderia levantar suspeita. E como é uma comunidade carente, se um tem direito a ganhar eu também tenho. Não é todos que sabem que só tem leite para a mãe que é HIV. (P13)

As informações das relações de vizinhança podem se constituir como um risco quanto a possibilidade de quebra de sigilo. Nesse sentido, o exemplo acima mostra a potência do trabalho da ESF, na medida em que a atenção singularizada proposta possibilita, inclusive, que sejam levados insumos à residência dos usuários quando necessário. Nesta perspectiva, o medo a respeito da quebra de sigilo também repercute em outros espaços de saúde do território, como no cotidiano das equipes dentro dos serviços:

Então isso foi até uma das discussões de como a pessoa vir aqui e pedir para fazer o teste, às vezes ela tem vergonha de "ah eu vim aqui para fazer o teste de HIV" Então a gente, às vezes quando orienta no acolhimento a gente 
escreve num papel, escrito Teste, e diz, "ó tu vai ali na frente e entrega esse papel que daí a pessoa sabe o que que é". Mas eles tem um certo receio de fazer por ser conhecido e tal, está fazendo o teste. Então isso a gente conversa muito entre a equipe também para que a pessoa não se sinta muito prejudicada, porque é conhecida e não quer fazer o teste por isso. (P4)

Assim, no que se refere ao HIV/Aids, é necessário lançar um olhar minucioso e atento às práticas de cuidado, considerando as diversas sutilezas que permeiam as intervenções e as relações comunitárias. Nesta perspectiva, a fala deste ACS denota novamente a problemática do sigilo no território:

E aí toda a vez que ela [usuária] ia falar com algum profissional sobre a doença ela pedia para a pessoa jurar que não ia comentar com ninguém. Que era uma coisa muito séria, e ai a gente achava que era uma coisa pior mas não, ela tinha uma ideia de que ninguém iria se aproximar dela se soubessem que ela tinha a doença, que a aids estava ligada a morte, que ela iria morrer. (P13)

O ACS é um profissional que assume um papel particular na equipe, principalmente por ser morador da área adscrita e por ser o dispositivo social de ações voltadas à prevenção e promoção de saúde, lança-se um olhar para a presença deles enquanto um elo entre a equipe e comunidade. O terreno no qual o profissional atua é estruturado a partir de aspectos multifatoriais associados a complexidade do HIV/Aids no território. Pode-se perceber o que foi mencionado a partir da fala de uma enfermeira responsável pelos testes rápidos no pré-natal em uma unidade de saúde:

Eu tenho uma paciente, que ela não quer se tratar para ninguém saber que ela tem HIV, há mais de 16 anos que ela descobriu, ela não quer que o agente comunitário veja para ela não ter que tomar remédio, ela não quer tratar para ninguém saber. (P3) 


\section{Discussão}

Em relação ao elo construído entre os ACS, equipe e território, está clara a sua importância e funcionalidade, porém este encontro também acontece atravessado por tensionamentos. Ao longo da história, observou-se a determinação da ciência como a única forma válida de produção do conhecimento. Nesta lógica, o conhecimento adquirido por meio da experiência e vivência prática acabou por ser considerado menos legítimo (Henning, 2012). Observamos este fenômeno também presente no discurso dos profissionais da área da saúde que participaram da presente pesquisa quando hierarquizam o conhecimento acadêmico (técnico) e os conhecimentos dos ACS. Silva e Cardoso (2008) entendem que tal hierarquia pode ser explicada por meio da influência de um modelo médico hegemônico presente, o qual favorece a prevalência de práticas assistencialistas e uma visão biomédica do sujeito. Ao mesmo tempo que os profissionais da pesquisa reconhecem a importância do trabalho do ACS, ainda se observa uma dinâmica entre "nós" e "eles".

Tajfel (1978) descreve diversos funcionamentos intergrupais e o interjogo das discriminações entre grupos maioritários e minoritários: a diferença está dada pelo sentimento de pertencimento ao grupo que, teoricamente, apresenta atributos superiores (maioritários) que são passíveis de comparação aos minoritários. Dado este contexto, é possível relacionar as dinâmicas de grupo da equipe entre 1. equipe técnica (maioritários): médicos, enfermeiros e técnicos de enfermagem pertencentes à unidade de saúde como profissionais instrumentalizados e 2. minoritários (ACS e usuários): que são os ACS realizando sua prática de forma nômade e descolada do serviço de saúde, comparado muito mais a um membro da comunidade (usuário) do que um técnico específico em saúde (profissional) aos olhos da equipe.

Conforme visto ao longo deste estudo, os ACS possuem uma importante função na quebra do modelo biomédico na ESF e na transversalização da promoção em saúde. Sua atuação mostra-se, por vezes, abstrata em termos de diretrizes e funções 
específicas, por se tratar de uma política não hegemônica nos cotidianos da AB. Indo ao encontro do que foi vislumbrado nas entrevistas apresentadas, Pedraza e Santos (2017) mapearam os principais fazeres da profissão em cidades do Maranhão e apontaram as visitas domiciliares, educação em saúde e identificação e acompanhamento de grupos de risco como preponderantes.

As visitas domiciliares, por exemplo, podem tornar-se mecanismos de intermédio e comunicação entre as famílias e a unidade básica de saúde, visando a identificação de demandas, distribuição de insumos, atenção multidisciplinar com os usuários para que se vinculam ao serviço e educação em saúde, como as salas de espera referidas pela P6. Nesta direção, Seoane e Fortes (2009) reforçam que a proximidade com os usuários pode permitir que eles se sintam mais à vontade para falarem abertamente sobre suas dúvidas e questões ao ACS em visitas domiciliares, por exemplo, em contraponto à formalidade das consultas.

Assim, no tocante ao trabalho com HIV/Aids no território, a visita domiciliar mostra-se como um recurso importante. Por outro lado, Ferraz e Nemes (2012) realizaram um estudo em São Paulo em que compreendem as visitas domiciliares como práticas que colocam os ACS em uma posição de controle e vigilância da comunidade, identificados como "pegando no pé" dos usuários. Tal problemática ressalta a linha tênue entre cuidado e controle.

Zambenedetti e Both (2013), compreendem que o ACS exerce uma posição paradoxal na qual, por mais que haja a inserção do funcionário na equipe de profissionais, ainda há uma dificuldade em entender se certas informações do usuário podem ser consideradas como "informação em saúde" ou "fofoca". Isso se dá uma vez que, diferentemente dos demais profissionais, o ACS tem acesso tanto a informações provenientes do serviço quanto àquelas compartilhadas pela vizinhança, sendo assim, a diferenciação entre profissional e morador do território torna-se ainda mais tênue. 
O trabalho do ACS possibilita que a unidade de saúde consiga acessar sujeitos marginalizados no território. O diálogo relatado por P3 e P5 realizado entre ACS e cafetões de uma região da cidade que possibilitou que as profissionais do sexo recebessem orientações de prevenção e a realização do teste rápido dentro de uma casa noturna.

A respeito da percepção dos usuários sobre a atuação dos ACS nas equipes um estudo aponta que estes são considerados enquanto facilitadores do acesso ao Serviço de Saúde, porém não são concebidos enquanto profissionais de saúde da equipe, indo ao encontro do que foi encontrado no presente estudo (Seoane \& Fortes 2009). Nesse sentido, consta na redação de documentos do SUS a proposta de lateralidade do saber. Esta visa colocar lado a lado todos os saberes envolvidos nos processos de saúde como o saber técnico científico e o saber do território, construído a partir de sua historicidade (Vanderlei \& Almeida, 2007). Esta lógica de ação ainda se mostra desafiadora às equipes, o que reflete os dados encontrados. O reconhecimento do saber dos ACS e do território não é posto em lateralidade com o saber científico, sendo os ACS colocados em posições de aprender e receber conhecimentos mais do que transmiti-los ou trocá-los com o restante da equipe.

Com a implementação de políticas sociais e de saúde voltadas ao enfrentamento do HIV/Aids, os atravessamentos do estigma tomam um formato velado, que penetra as relações das comunidades e as práticas dos profissionais que atuam com esta população no território. De acordo com Goffman (2008), o estigma pode ser definido como um fenômeno no qual há uma desqualificação do indivíduo perante os outros. Ele acaba tomando uma posição de não apenas atributo individual, mas como uma ferramenta que estimula processos de exclusão e aumento de desigualdades (Parker \& Aggleton, 2003).

O preconceito e segregação relacionados HIV/Aids, presentes na fala dos participantes, pode estar relacionado ao estigma que permeia a história do vírus. P3 e 
P13 trazem a dificuldade de usuários soropositivos buscarem o atendimento na $A B$, tendo em vista o medo de ter seu diagnóstico descoberto e de sofrerem retaliações por parte da comunidade. Assim, estudos compreendem que o HIV/Aids, por ser caracterizado como uma infecção transmitida por meio do ato sexual, está fortemente associado a julgamentos morais relacionados ao sexo e à sexualidade (Ew et al., 2018).

Seffner e Parker (2016) trazem o atual cenário das políticas públicas brasileiras relacionadas ao HIV/Aids, encontrando um paradoxo: há um tensionamento entre "fazer viver" e "deixar morrer". Os avanços em tecnologia médica, visando o exame sorológico e o acesso gratuito à medicação antirretroviral, não são suficientes para o enfrentamento do vírus. É necessário reconhecer a dimensão política e social do portador e do diagnóstico sorológico.

Em relação à oferta diagnóstica do teste rápido de HIVIAids e outras IST's na $A B$, Zambenedetti e Silva (2015) problematizam a territorialização e analisam a relação paradoxal implicada no cenário: o processo visa facilitar o acesso e propiciar que a equipe esteja inserida no contexto social e cultural dos usuários, facilitando a criação de vínculo. Por outro lado, conforme visto nas entrevistas, o território pode assumir um significado ambivalente.

Assim, quando abordados os discursos relacionados à presença do ACS nas unidades de saúde e o teste rápido de HIV/Aids, é necessário lançar olhar para a historicidade e os significados além diagnóstico. Além disso, as repercussões decorrentes de uma concepção ainda estigmatizante de sujeitos persiste habitando as trajetórias comunitárias.

O medo da quebra de sigilo enquanto barreira de acesso para realização do teste está além da presença e ação dos ACS no território, relaciona-se com a dinâmica de trabalho da $A B$ como um todo. Isto foi exemplificado no trecho apresentado nos resultados sobre o dilema da entrega do leite para a usuária soropositiva. Nesta 
situação, a profissão ocupada por quem levaria o insumo não era a centralidade da cena, mas sim a complexa missão que a $A B$ tem de garantir a equidade dos usuários preservando o sigilo das informações.

\section{Considerações finais}

A contribuição deste artigo contempla a potência da atuação dos ACS na política de HIV/Aids na $A B$ no sentido de produção de autonomia, cidadania de sujeitos e capilaridade da $A B$ nos territórios. O ACS configura-se enquanto um dispositivo de elo, que aproxima os serviços de saúde ao cotidiano e redes comunitárias como nunca antes na história das políticas de saúde no Brasil, o que surge como aversivo à atual conjuntura macropolítica e social do país. Este embate vem crescendo com as modificações na política que extinguem a obrigatoriedade do ACS dentro das equipes da ESF - sendo esse o principal dispositivo de atenção à saúde no SUS.

O trabalho dos ACS na política de HIV/Aids no território mostra-se paradoxal no sentido que possibilita maior vinculação do usuário ao serviço, ampliando o acesso ao teste rápido e acompanhamento do usuário. Ao mesmo tempo, há um desafio que exige criatividade no fazer dos ACS quanto à manutenção do sigilo das informações, tendo em vista a posição que ocupam. A complexidade da atuação dos ACS por vezes é invisível aos olhos do Estado, considerando a precarização dos espaços de educação permanente em saúde ofertados a estes.

É de suma importância que sejam construídos espaços de intervenções nas equipes para compreender a intersecção da prática com a temática de HIV/Aids no território, abarcando o histórico de estigma e preconceito relacionado ao vírus. Tais estratégias podem se desdobrar no relacionamento entre a equipe e facilitar os processos de trabalho previstos para o ACS. O estudo foi conduzido com diversos profissionais da $A B$ de Porto Alegre, o que possibilitou uma ampla gama de percepções sobre o fazer 
dos ACS. No entanto, não foram aprofundadas especificidades no tocante a este ofício. Sugere-se que próximos estudos possam dar enfoque às percepções dos ACS sobre o seu trabalho e que sejam realizados em outras regiões do país.

\section{Referências}

Brasil, Ministério da Saúde. Secretaria de Atenção à Saúde (2012). Política Nacional de Atenção Básica. Brasília: Ministério da Saúde.

Braun, V., \& Clarke, V. (2013). Teaching thematic analysis: Overcoming challenges and developing strategies for effective learning. Qualitative Research in Psychology, The psychologist, 26(2), 120-123.

Christensen, P. B., \& Karlquist, S. (1990). Impacto de Los Promotores de Salud en una Zona de Barrios Pobres de Pucallpa, Perú. Boletín Oficina Sanitaria Panamericana, 109(2), 134-144.

Dullak, R., Rodriguez-Riveros, M. I., Bursztyn I., Cabral-Bejarano, M. S., Ruoti, M., Paredes, M. E., Molinas, F. (2011). Atención Primaria en Salud en Paraguay: panorámica y perspectiva. Clínica e Saúde Coletiva, 16(6), 2.865- 2.875

Ew, R. D. A. S., Ferreira, G. S., Moro, L. M., \& Rocha, K. B. (2018). Estigma e teste rápido na atenção básica: percepção de usuários e profissionais. Revista Brasileira em Promoção da Saúde, 31(3), 1-11.

Ferraz, D. A. D. S., \& Nemes, M. I. B. (2012). Prevenção das DST e aids na atenção primária à saúde: reflexões sobre as práticas a partir do estudo de uma Unidade de Saúde da Família. In Vulnerabilidade e direitos humanos: prevenção e promoção da saúde: da doença à cidadania-Livro I. Curitiba: Juruá, 86-92.

Flick, U. (2009). Introdução à pesquisa qualitativa. Porto Alegre: Artmed. 
Goffman, E. (2008). Estigma: notas sobre a manipulação da identidade deteriorada. Rio de Janeiro: Guanabara.

Gomes, C.B., Gutiérrez, A.C., \& Soranz, D. (2020). Política Nacional de Atenção Básica de 2017: análise da composição das equipes e cobertura nacional da Saúde da Família. Ciência \& Saúde Coletiva, 25(4), 1327-1338.

Hamann, C., Pizzinato, A., Weber, J. L. A., \& Rocha, K. B. (2017). Narrativas sobre risco e culpa entre usuários e usuárias de um serviço especializado em infecções por HIV: implicações para o cuidado em saúde sexual. Saúde e Sociedade, 26(3), 651-663.

Henning, P. (2012). Resistência e criação de uma gaia ciência em tempos líquidos. Ciência \& Educação, 18(2), 487-502.

Macaia, A. F. (2014). Implementação do programa de agentes comunitários de saúde no âmbito dos serviços de saúde das forças armadas angolanas. Recuperado da

URL https://repositorio.ufmg.br/bitstream/1843/BUBD9ZCNME/1/afm_disserta_o_1 6_09_14.pdf

Marzari, C. K., Junges, J. R., \& Selli, L. (2011). Agentes comunitários de saúde: perfil e formação. Ciência \& Saúde Coletiva, 16, 873-880.

Parker, R., \& Aggleton, P. (2003). HIV and AIDS-related stigma and discrimination: a conceptual framework and implications for action. Social Science \& Medicine, 57(1), 13-24.

Pedraza, D. F., \& Santos, I. (2017). Perfil e atuação do agente comunitário de saúde no contexto da Estratégia Saúde da Família em dois municípios da Paraíba. Interações (Campo Grande), 18(3), 97-105.

Pizzinato, A., Rocha, K. B., De Oliveira-Machado, R., de Carvalho, F. T., \& NogueiraFreire, I. (2018). Strengths and weaknesses of rapid hiv test implementation in a specialized center in Brazil. Revista de Salud Pública, 20(5), 560-567. 
Rocha, K. B., Ew, R. D. A. S., Moro, L. M., Zanardo, G. L. P., \& Pizzinato, A. (2018). Aconselhamento na perspectiva de profissionais da atenção básica: desafios na descentralização do teste rápido HIV/Aids. Ciências Psicológicas, 12(1), 6778.

Santander, N. B. (2017). El rol del agente comunitario de salud. Recuperado da URL: http://repositorio.uchile.cl/handle/2250/168097.

Seffner, F., \& Parker, R. (2016). Desperdício da experiência e precarização da vida: momento político contemporâneo da resposta brasileira à aids. InterfaceComunicação, Saúde, Educação, 20, 293-304.

Seoane, A. F., \& Fortes, P. A. D. C. (2009). A percepção do usuário do Programa Saúde da Família sobre a privacidade e a confidencialidade de suas informações. Saúde e Sociedade, 18(1), 42-49

Silva, N. H. L. P. D., \& Cardoso, C. L. (2008). Agentes comunitários de saúde: sentidos acerca do trabalho em HIV/AIDS. Psicologia \& Sociedade, 20(2), 257-266.

Tajfel, H. E. (1978). Differentiation between social groups: Studies in the social psychology of intergroup relations. [s. I.] : Academic Press.

Vanderlei, M. I. G., \& Almeida, M. C. P. D. (2007). A concepção e prática dos gestores e gerentes da estratégia de saúde da família. Ciência \& Saúde Coletiva, 12, 443-453.

Zambenedetti, G., \& Both, N. S. (2013). "A via que facilita é a mesma que dificulta": estigma e atenção em HIV-Aids na Estratégia Saúde da Família. Fractal: Revista de Psicologia, 25(1), 41-58.

Zambenedetti, G., \& Silva, R. A. N. D. (2015). O paradoxo do território e os processos de estigmatização no acesso ao diagnóstico de HIV na atenção básica em saúde. Estudos de Psicologia (Natal), 20(4), 229-240. 


\section{Declaração do contributo dos autores}

KR e AS contribuíram no desenho e implementação da investigação, KR, AS, RE, AG e DS na análise dos resultados e na escrita do manuscrito. Todas as autoras discutiram os resultados e contribuíram para a versão final do manuscrito.

\section{Editor de sección}

La editora de sección de este artículo fue Pilar Bacci.

ORCID ID: 0000-0002-6611-1905

\section{Formato de citación}

Rocha, K. B., Silveira, A. C. T., Gazzola, A. F. G., Silva, D. V., \& Eifler, R. P. (2020). O trabalho dos Agentes Comunitários de Saúde (ACS) na política de HIV/aids. Psicología, Conocimiento y Sociedad, 10(3), 27-49. doi: http://dx.doi.org/10.26864/PCS.v10.n3.2 